\title{
O (NÃO) FUNCIONAMENTO DA REESCRITA EM TEXTOS PRODUZIDOS POR LICENCIANDOS EM LETRAS
}

\section{THE (NON) EFFECTIVENESS OF TEXTS IN REWRITINGS PRODUCED BY TEACHERS IN TRAINING}

\author{
Elisa Cristina Amorim Ferreira* \\ Denise Lino de Araújo
}

\begin{abstract}
RESUMO
Estudos apontam o funcionamento da reescrita como etapa de melhoramento do texto. Todavia, experiências empíricas nos indicaram que nem sempre a reescrita funciona conforme o esperado. A partir dessas observações, realizamos pesquisa sobre atividades de reescrita com professores em formação inicial, entre os quais identificamos sujeitos que, supostamente, deveriam dominar a produção textual, mas que revelaram pouco domínio dessa atividade, necessitando, portanto, da didatização da reescrita. O objetivo da pesquisa foi identificar e analisar os fatores que contribuem (ou não) para a reescrita textual no ensino superior. Os fundamentos teóricos recuperam os estudos sobre escrita de Kato (1993), Meurer (1997) e Sautchuk (2003), além de trabalhos sobre a reescrita elaborados por Jesus (1995), Ruiz (2001), Antunes (2003), entre outros. A metodologia, de inspiração interpretativista, segue os procedimentos dos trabalhos documentais e exploratórios. A análise revela a existência de dois fatores complexos e imbricados que contribuem tanto para o funcionamento quanto para o não funcionamento da reescrita textual no ensino superior: a correção do sujeito professor e a experiência com a escrita do sujeito licenciando produtor. Há uma tendência de a correção favorecer a passividade do produtor; concomitantemente, há outra tendência que é a da reversão dessa passividade, mas esta depende do engajamento do produtor na atividade de reescrita. Os dados mostram que essa segunda tendência é menos recorrente. Palavras-chave: reescrita; Ensino Superior; correção de texto.
\end{abstract}

\section{ABSTRACT}

Studies point to the effectiveness of rewriting as a step to text improvement. However, empirical research has shown that rewriting does not always work as expected. From these observations, research activities have been carried out with teachers in training and subjects who were supposed to dominate the textual production, but showed little practice in this

\footnotetext{
* UFCG, Campina Grande (PB), Brasil. elisacristina@msn.com; UFCG, Campina Grande (PB), Bra-
} sil. deniselinoaraujo@gmail.com 
area, therefore requiring the didactization rewriting. The objective of this research is to identify and analyze factors that contribute (or not) to rewrite the textual of higher education. The theoretical framework involves the writing of Kato (1993), Meurer (1997) and Sautchuk (2003), and works on rewriting prepared by Jesus (1995), Ruiz (2001), Antunes (2003), among others. The methodology of interpretive inspiration follows the procedures of documentary work and exploration. The analysis has revealed the existence of two intertwined and complex factors that contribute to both the effectiveness and non-effectiveness to rewrite the text in higher education: the correction of the subject teacher and the experience of writing the subject's producer licensing. There is a tendency to fix foster passivity producer; concomitantly, there is another trend that is the reverse of this passivity, but this depends on the engagement of the producer activity in the rewrite. The data show that this tendency is less the second applicant.

Keywords: rewriting; higher education; text correction.

\section{CONSIDERAÇÕES INICIAIS}

A escrita pressupõe etapas interdependentes e intercomplementares de realização, cada qual com uma função específica e uma cota de colaborações na versão final do texto produzido. A reescrita é uma dessas etapas que foi didatizada, a fim de tornar o processo de escrita mais acessível ao nível dos alunos da educação básica.

Embora, de modo geral, estudos apontem para o funcionamento da reescrita enquanto etapa de reflexão, revisão, avaliação e melhoramento do que foi escrito e por ser considerada uma atividade cujo exercício colabora para a formação proficiente e crítica do aluno/escritor, dados obtidos a partir de conversas com professores e da própria experiência como escritoras e como docentes, indicam que nem sempre a reescrita funciona a contento.

A partir dessas observações, debruçamo-nos sobre atividades de reescrita em nível superior de ensino, buscando responder a seguinte questão de pesquisa: que fatores contribuem para o (não) funcionamento da reescrita em textos produzidos por licenciandos em Letras? Em decorrência, objetivamos: (1) identificar e (2) analisar os fatores que contribuem ou não para reescrita textual no nível de ensino já referido.

A relevância desta investigação fundamenta-se na atenção dada recentemente pelos estudiosos à escrita acadêmica, pois, supostamente, quem chegava ao ensino superior teria proficiência na escrita. Contudo, resultados de pesquisas das mais diversas áreas mostram que quem tem acesso a esse nível de ensino não necessariamente tem domínio da escrita, muito menos da escrita típica da esfera acadêmica, necessitando de didatização do processo de reescrita. 
Este artigo estrutura-se a partir do seguinte plano organizacional: considerações iniciais; percurso metodológico; pressupostos teóricos da pesquisa; seções analíticas e, por último, as conclusões.

\section{INDICAÇÕES METODOLÓGICAS}

A investigação realizada insere-se no campo da Linguística Aplicada, caracteriza-se como uma pesquisa de natureza qualitativa e estabelece-se no campo das pesquisas exploratórias de viés documental (cf. MOREIRA E CALEFFE, 2006), já que seu corpus de análise é composto por documentos, mais especificamente, atividades de reescrita de alunos dos períodos iniciais de um curso de Licenciatura Plena em Letras, de uma universidade pública. Assim, obtivemos: 54 documentos (dentre escritas e reescritas de resumos, resenhas e análise de provas ${ }^{1}$ ).

Vale salientar que, apesar de a pesquisa ser interpretativista, utilizamos, devido ao número de documentos analisados, recursos quantitativos na organização de recorrências importantes, para termos uma visão geral desses dados e, assim, atingir objetivos analíticos qualitativos.

O processo de categorização utilizado pautou-se em dois grandes grupos: 1) fatores que contribuem para o funcionamento e 2) fatores que contribuem para o não funcionamento. Ou seja, duas categorias de análise complexas e indissociadas.

\section{FUNDAMENTOS TEÓRICOS}

Com a finalidade de revelar a complexidade do objeto que nos propomos a analisar e de fundamentá-lo teoricamente, recobrimos algumas das principais teorias de escrita e alguns dos mais conhecidos trabalhos sobre reescrita. Para tanto, dividimos esse percurso teórico em quatro subseções que serão apresentadas sinteticamente a seguir.

\subsection{Teoria cognitiva}

A teoria cognitiva baseia-se no modelo dos processos de composição da escrita elaborado por Hayes e Flower (1980) a partir da análise de protocolos ver-

\footnotetext{
1 Nomeamos os documentos de acordo com suas naturezas (escrita - E ou reescrita - R) e, em seguida, por ordem alfabética marcada por numeração crescente. Assim teremos: E1 a E27 e R1 a R27.
} 
bais de sujeitos letrados. $\mathrm{O}$ ato de escrever, nessa visão componencial, compreende meta, etapas e fases ou conjuntos de processos.

A reescrita não é aparentemente delineada, nesse modelo, nem possui maior destaque nas explanações de Kato (1993), contudo, sua ideia pode ser percebida nas etapas do monitoramento desempenhado pelo produtor em todo o processo e, sobretudo, na revisão. Em ambas, o autor debruça-se sobre seu texto, lendo-o, monitorando-o a fim de "editorá-lo" e "corrigi-lo", o que nos remete a uma concepção clássica de reescrita.

Por fim, reescrita, nesse modelo, baseia-se na clareza que o produtor tem da tarefa que se impõe. Essa é uma etapa da revisão, cuja finalidade é a de aproximar o texto ao projeto inicialmente planejado, sendo assim, uma das limitações da perspectiva cognitiva.

\subsection{Teoria sociocognitiva}

O texto escrito, enquanto manifestação da linguagem, além de sua configuração linguística, conforme a teoria sociocognitiva apresentada em Meurer (1997), apresenta duas dimensões constitutivas: a psicológica, segundo a qual a linguagem é uma forma de cognição; e a social que tem a linguagem como instrumento de ação social e interação indivíduos/meio.

Com base nessa perspectiva, o autor supracitado expõe-nos um modelo recursivo de produção de textos escritos, que, por ter um olhar fundamentalmente teórico, assim como a teoria cognitiva, não define claramente o que seja reescrita e sua prática. Verificamos, todavia, que a reescrita está representada pelas operações de recomposição e polimento do texto, e, também, pelas ações do monitor - "responsável pela geração de ideias, planejamento, organização, execução e editoração das várias partes do texto" (p.21).

A permanente ativação do monitor em ambos os modelos cognitivo e sociocognitivo e a recursividade das etapas, no entanto, só se dão quando o escritor tem proficiência de escrita, sendo capaz de ler seu texto, examinando-o e integrando todos os módulos simultaneamente, podendo reelaborá-lo quantas vezes o monitor indicar, resultando em um texto adequado do ponto de vista linguístico e sociocognitivo.

Um escritor não proficiente tenderia a dar por finalizada a produção textual após a escrita. Isso significa que o escritor não realiza os módulos que poderiam corresponder à reescrita e, em alguns casos, quando os realiza preocupa-se apenas com aspectos microestruturais. 


\subsection{Teoria interacionista}

A teoria interacionista, de acordo com Sautchuk (2003), entende o texto como uma unidade linguística, semântico-formal e pragmática. $\mathrm{O}$ ato de escrever, por sua vez, é uma produção dialógica, interativa entre dois enunciadores construídos linguística e psicossocialmente: um emissor (indivíduo-escritor) e um receptor (leitor externo) que operam dialogicamente o texto num processo simultâneo cuja missão é produzir sentido. O indivíduo-escritor, por ser um indivíduo de face bifurcada, age sob dois pontos de vista: o de enunciador que realmente escreve o texto (escritor ativo) e o de co-enunciador que lê, monitora e dirige o que deve ser reescrito (leitor interno).

A elaboração de um texto escrito, assim, exige o equilíbrio entre o escritor ativo e o leitor interno e as habilidades de ambos, que derivam de uma série muito complexa de fatores desde os textuais até os de natureza cognitiva.

A partir dessas exposições verificamos que o "ser" significativo na etapa de reescrita é, especificamente, ser o leitor interno ao qual cabe fazer a releitura do material escrito, reinterpretar a informação para ver se está de acordo com a interação em processo e confirmá-la. O leitor interno seria o monitor da teoria sociocognitiva. O texto mal elaborado, dessa maneira, surgiria quando o leitor interno não é acionado devidamente e o texto passa a ser escrito apenas na perspectiva do escritor-ativo, ou seja, o texto não passa por uma reescrita consecutiva à escrita ou posterior a ela.

\subsection{Trabalhos sobre reescrita: perspectiva didática}

Conforme Antunes (2003), a escrita compreende planejamento, operação e revisão/reescrita. A última etapa, a qual nos interessa, é o momento de análise e melhoramento do texto, verificação da execução do objetivo, do atendimento à temática, da macro e da microestrutura textual.

Quanto à prática da reescrita, Jesus (1995) salienta que essa não é estável, ao contrário, varia substancialmente em decorrência dos envolvidos. Num ambiente de ensino-aprendizagem, por exemplo, Ruiz (2001) observa que o trabalho realizado pelo aluno decorre da interferência do professor efetivada por meio da correção da primeira versão do texto do educando. Os tipos de correção, por sua vez, podem resultar em maneiras diferentes de pensar e realizar a reescrita. Seriam elas: a reescrita pós-indicações - reescrita pode ou não acontecer, porque o aluno pode não saber solucionar o problema sinalizado pelo professor ou, até mesmo, o aluno pode não compreender a correção; a reescrita pós-resoluções - reescrita como simples tarefa de 
copiar as soluções já apresentadas pelo docente para os problemas, reescrita pós-classificações - reescrita que, assim como as pós-indicações, pode ou não ocorrer, apesar de trazer resultados melhores que esta; e a reescrita pós-"bilhete" textual-interativo - reescrita que tem tido melhores resultados qualitativos em relação ao texto e à aprendizagem, pois os aprendizes reescrevem à medida que respondem aos "bilhetes", sendo levados, em muitos casos, à reflexão.

Há ainda, quando se trata da literatura sobre reescrita, uma tipologia de movimentos ou operações linguísticas encontradas nesse momento da construção do texto escrito. Conforme Fabre (1986 apud CÁLIS, 2008, p.61), são quatro essas operações: acréscimo, supressão, substituição e deslocamento. O acréscimo é a adição de um elemento gráfico, acento, pontuação, palavra, sintagma ou frase. A supressão consiste na retirada, sem substituição do seguimento suprimido podendo aplicar-se sobre unidades diversas. Já a substituição corresponde a uma supressão seguida da substituição por um novo termo. Tem-se, também, a operação de deslocamento que corresponde à permutação de elementos, que leva a modificar a ordem de elementos no processo de encadeamento textual.

\section{QUANDO A REESCRITA FUNCIONA}

A reescrita é uma maneira de aprendermos sobre o funcionamento da língua escrita enquanto trabalhamos nela e com ela na busca de melhoramento textual. Com essa etapa da escrita, tanto o caráter processual do texto ganha destaque, mesmo quando esta é aparentemente "desmembrada" da escrita pela didatização, como o aspecto reflexivo sobre as práticas, operações, procedimentos e estratégias de retorno ao já dito, que inclui retomadas, reelaborações, escolhas, abandonos e mudanças, ganha relevo.

De posse do nosso conjunto de dados, verificamos a presença de operações ou movimentos linguísticos descritos na literatura especializada como típicos da reescrita que, conforme dispusemos na seção Trabalhos sobre reescrita: perspectiva didática embasando-nos em Fabre (1986 apud CÁLIS, 2008), constituem-se em quatro tipos: supressão, acréscimo/adição, deslocamento e substituição, os quais podemos observar no fragmento de R10 quando o confrontamos com o fragmento de E10. 
ESCRITA: (Sinalizações de correções) E10

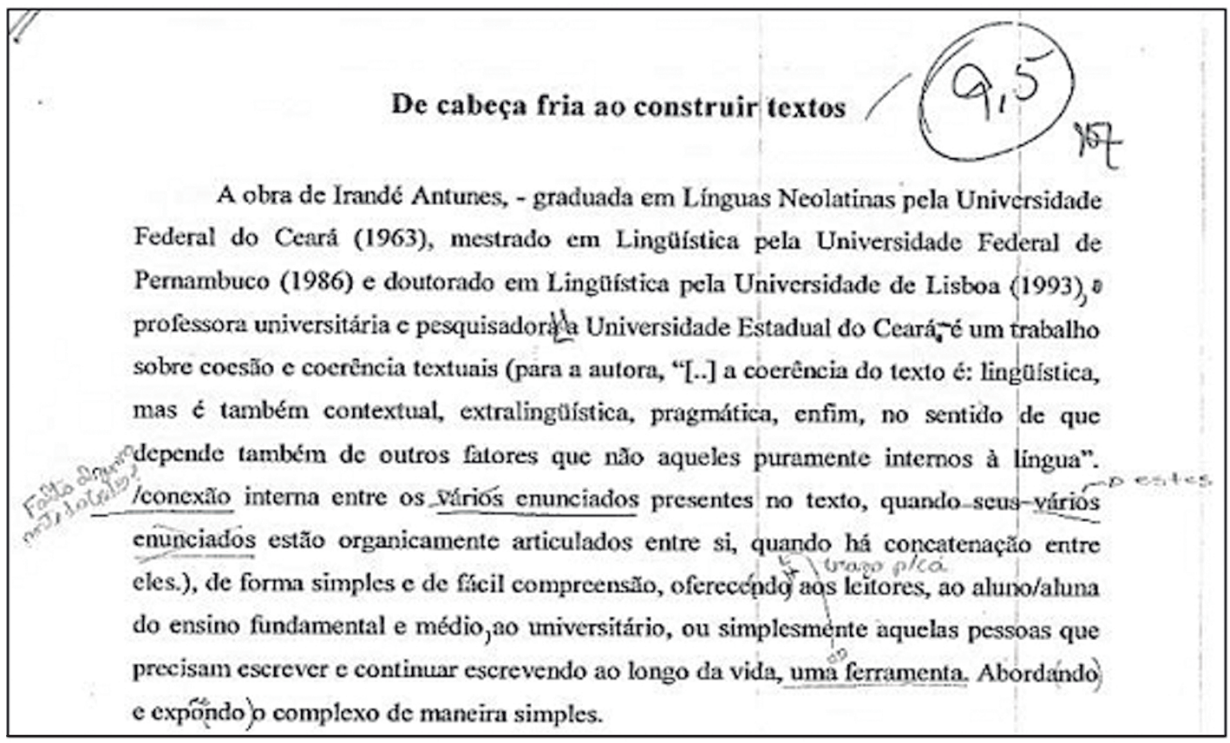

REESCRITA: (Movimentos de reescrita) R10

\section{O complexo torna-se simples (SUBSTITUIÇÃO)}

A obra de Irandé Antunes, - graduada em Línguas Neolatinas pela Universidade Federal do Ceará (1963), mestrado em Lingüística pela Universidade Federal de Pernambuco (1986) e doutorado em Lingüística pela Universidade de Lisboa (1993),(ACRÉSCIMO) professora universitária e pesquisadora da (SUBSTITUIÇÃO) Universidade Estadual do Ceará-(ACRÉSCIMO) é um trabalho sobre coesão e coerência textuais (para a autora, " [...] a coerência do texto é: lingüística, mas é também contextual, extralingüística, pragmática, enfim, no sentido de que depende também de outros fatores que não aqueles puramente internos à língua". /é (ACRÉSCIMO) conexão interna entre os [vários] (SUPRESSÃO)enunciados presentes no texto, quando estes (SUBSTITUIÇÃO) estão organicamente articulados entre si, quando há concatenação entre eles.), de forma simples e de fácil compreensão, oferece (SUBSTITUIÇÃO) uma ferramenta (DESLOCAMENTO) aos leitores, ao aluno/aluna do ensino fundamental e médio,(ACRÉSCIMO) ao universitário, ou simplesmente àquelas (ACRÉSCIMO) pessoas que precisam escrever e continuar escrevendo ao longo da vida. Aborda (SUBSTITUIÇÃO) e expõe (SUBSTITUIÇÃO) o complexo de maneira simples.

A resenha do livro Lutar com palavras: coesão e coerência, apresentada acima, mesmo em sua escrita (versão inicial) já atendia satisfatoriamente às especificidades do gênero, do aspecto discursivo ao linguístico, tendo sido considerada boa ao ponto de receber quase a nota máxima $(9,5)$ e, ao fim, a apreciação de "Boa resenha!". To- 
davia, ainda ganhou sinalizações de correção pelo sujeito corretor como verificamos em E10, marcações de cunho resolutivo, indicativo e textual-interativo.

Salta-nos aos olhos, ao analisarmos R10, a quantidade de movimentos realizados pelo sujeito licenciando e a presença, mesmo que não homogênea, dos quatro movimentos em uma reescrita cuja versão inicial tinha sido avaliada como boa. Considerando essas ações caracterizadoras da reescrita, podemos, portanto, dizer que houve um evidente comprometimento com a atividade, na qual o sujeito produtor debruçou-se sobre seu texto, engajado no trabalho de melhorá-lo, realizando modificações textuais guiadas pela correção e por sua autonomia enquanto escritor, nitidamente marcada pelas doze modificações realizadas sem indicação do corretor, das quais trataremos a posteriori, e pelas manutenções.

Como vimos, o exemplo R10 apresenta os quatro tipos de movimentos de reescrita descritos na literatura, ocorrência que, ao analisarmos todo o corpus, estendeu-se para um grupo de dezesseis das vinte e sete reescritas; as demais (onze) reescritas apresentaram pelo menos uma forma de movimento. Constatamos que essas não foram, todavia, as únicas operações observáveis no corpus. Um quinto movimento pode ser identificado, cuja recorrência correspondeu a 93 casos, revelando-se, assim, um dado significativo. O movimento de manutenção, como denominamos, caracteriza-se pela conservação na reescrita de um dado elemento que foi sinalizado pelo corretor como passível de alteração; está sendo também entendido, neste trabalho, como um movimento encapsulador, pois tem a capacidade de apresentar como subtipos os quatros tipos de operações descritos na literatura.

Em decorrência dessas particularidades, a manutenção é um movimento que só pode ser visto nas reescritas cujas versões iniciais/escritas receberam alguma forma de correção que, geralmente, é realizada por um professor, contrapondo-se, desse modo, à supressão, ao acréscimo, ao deslocamento e à substituição que podem aparecer tanto em reescritas didatizadas, como é o caso das investigadas aqui, quanto nas reescritas processuais não didatizadas, ou seja, as realizadas sem correção prévia por outro sujeito que não o produtor.

Ainda sobre essa questão vemos que, se a escrita é uma atividade construída essencialmente na interação entre enunciador e leitor, a reescrita enquanto etapa da escrita, de acordo com Gaffuri e Menegassi (2010), seria um processo no qual "professor e aluno dialogam responsivamente para a construção textual" (p. 1), portanto, quando o movimento de manutenção ocorre, implica em falha nesse diálogo entre o eu e o outro. Tomemos um fragmento de E10 e R10 como exemplificação: 
FRAGMENTO 1: E10

\section{Sendo assim, o leitorl leitora vai conseguir apreender e compreender quich a coest̃o e a coerência não se dão apenas na linearidade da língua}

FRAGMENTO 2: R10

Sendo assim, o leitor/leitora conseguirá apreender
a coerência năo se dão apenas na linearidade da língua.

No fragmento 1: E10 há uma sinalização do corretor para supressão da palavra que, todavia, ao passarmos nossa atenção ao fragmento 2: R10, fica-nos clara a permanência na reescrita do que, não sendo apagado como indicado. Temos, assim, a configuração do não atendimento à sinalização e certamente devido à compreensão do autor de que o elemento sinalizado não devia ser eliminado.

Quando falamos sobre manutenção, referimo-nos a uma atividade responsiva diferente da esperada pelo corretor na reescrita, que, inicialmente, parece contribuir para o não funcionamento dessa etapa da escrita. Isso se deve à consolidação da ideia de que os comentários e sinalizações de correção do professor são tidos sempre como válidos e úteis para a construção textual, pois este, como escritor proficiente, tem a consciência da importância que suas ações têm no processo de produção do texto; contudo, como podemos comprovar a partir dos fragmentos 1: E10 e 2: R10 essa premissa não parece ser verdadeira.

O sujeito produtor de E10 e R10 demonstrou autonomia para ler e julgar se a sinalização de supressão traria progressos ou não para seu texto; se ele tivesse passivamente acatado a sugestão do corretor, teria afetado negativamente seu texto indo contra os princípios de melhoria da reescrita.

Outro aspecto importante, e que segue a mesma perspectiva autônoma e engajada da manutenção, diz respeito às alterações realizadas pelo sujeito produtor sem indicação de correção. Essas alterações, por serem iniciativas do próprio produtor, apresentam apenas as quatro operações de reescrita descritas na literatura, isto é, a operação de manutenção não ocorre. Apesar disso, ambas, manutenção e alterações sem sinalização, estão interligadas pela autonomia do sujeito produtor que se empenha na tarefa de retrabalhar seu texto, com o intuito de torná-lo mais claro e coeso e ajustar intenções para melhor atingir seu objetivo comunicativo. Quantitativamente, ao atentarmos para os números gerais, observamos que nas vinte e sete reescritas, temos um total de 352 alterações do sujeito produtor sem indicação de correção. Dos vinte e sete sujeitos produtores apenas quatro não rea- 
lizaram essa forma de alteração, o que sugere uma preocupação quase coletiva com o melhoramento textual e configura a assunção, por parte desses sujeitos licenciandos, de um papel ativo perante seu texto.

Ao somarmos essas 352 alterações voluntárias aos 93 movimentos voluntários de manutenção existentes no corpus, temos, então, outro número expressivo: 445 alterações/movimentos de sujeitos pensantes, engajados com a atividade de reescrever, contrapondo-se a 344 operações de reescrita (supressão, acréscimo, deslocamento e substituição) realizadas por sugestões do corretor. Ou seja, uma diferença de 102 mudanças entre o voluntário e o sugerido no corpus.

Podemos tomar como exemplo R18 em comparação com E18 que apresenta dezenove alterações realizadas pelo produtor por conta própria, dentre as quais podemos expor os fragmentos abaixo: escrita e, após, reescrita.

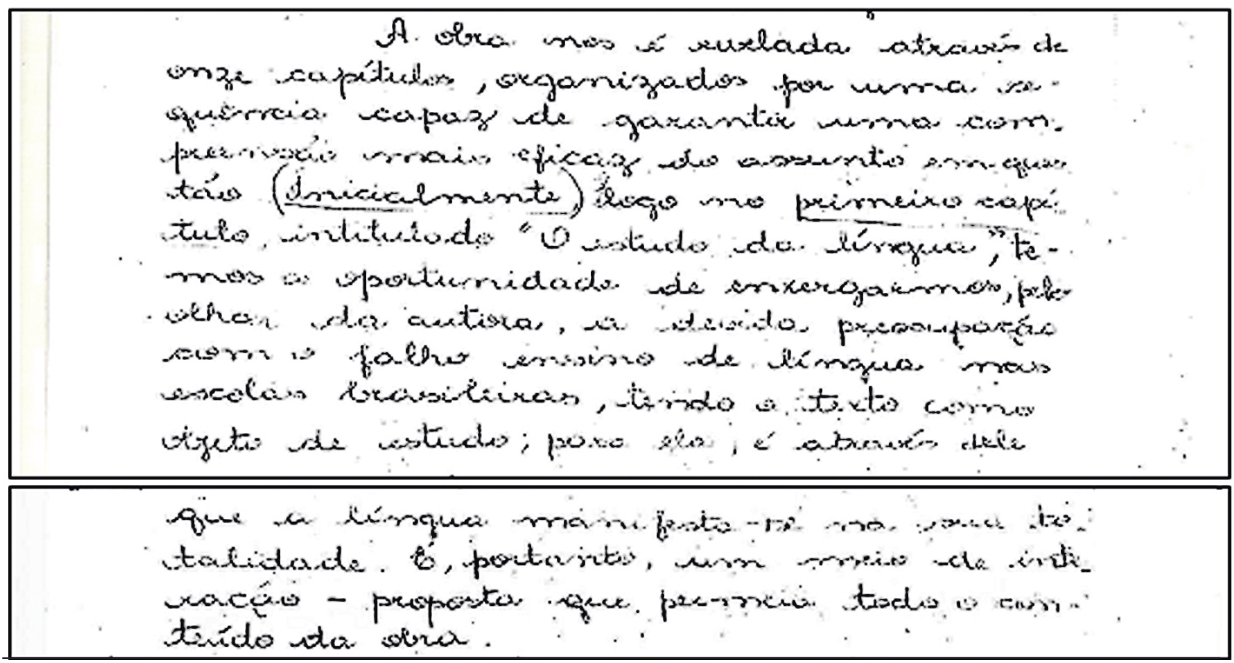


FRAGMENTO 4: R18

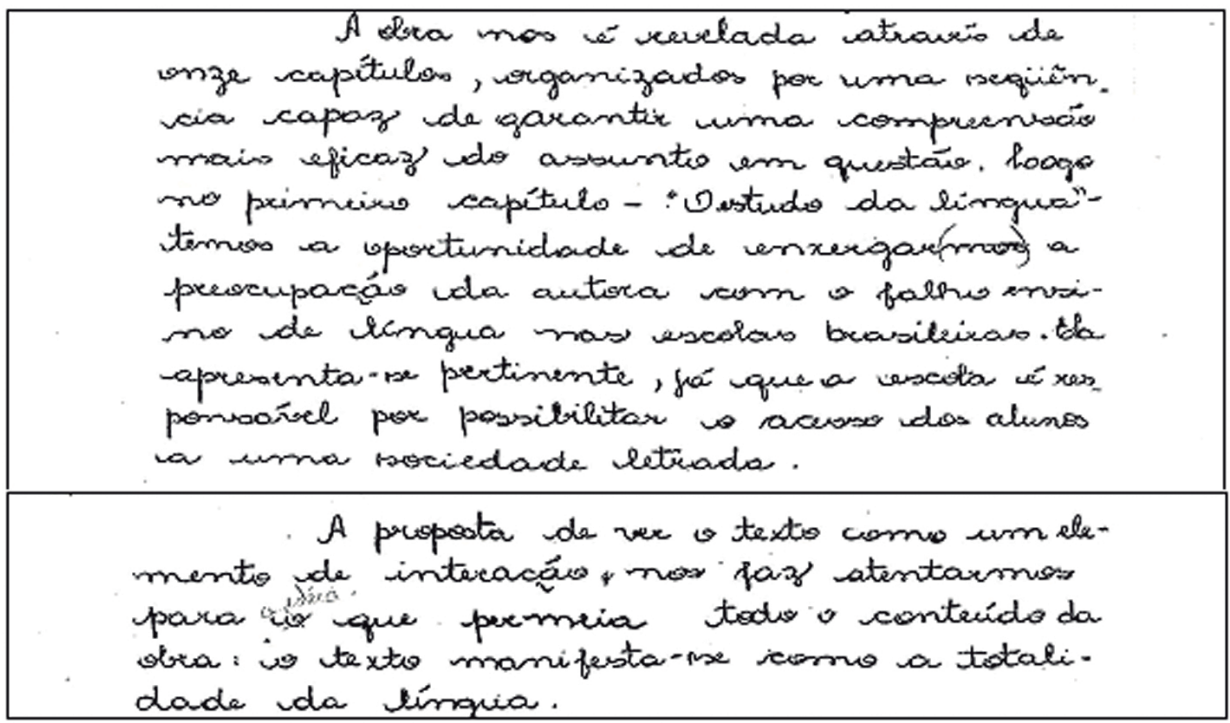

O exemplar 18 do nosso corpus é uma resenha também do livro Lutar com palavras: coesão e coerência e partilha da mesma nota que a resenha antes analisada. Esses fragmentos destacados são representações de como as alterações de cunho voluntário podem contribuir para o crescimento qualitativo do texto e também para o amadurecimento do sujeito enquanto escritor autônomo.

Há notoriamente diferenças entre R18 e E18, algumas por sugestão do corretor e outras espontâneas, dentre essas, duas são mais expressivas. A primeira é o acréscimo do trecho "Ela apresenta-se pertinente, já que a escola é responsável por possibilitar o acesso dos alunos a uma sociedade letrada.", uma modificação importante, já que altera a informatividade e a argumentatividade, aspectos essenciais no gênero resenha. A segunda corresponde à substituição de um trecho por um parágrafo, desenvolvendo melhor a ideia contida no trecho inicial. Em outras palavras, temos um sujeito licenciando que leu e refletiu sobre seu texto agindo em níveis mais profundos da textualidade com o intuito de melhorá-lo, um sujeito que se colocou no lugar do outro (leitor do seu texto), ativando o que Sautchuk (2003, p.19) denominou leitor interno.

Uma apreciação dos significados dessas alterações voluntárias no corpus, de modo geral, ratificou o observado a partir de E18 e R18: o melhoramento da reescrita em comparação com a escrita. Além do mais, constatamos que as alterações realizadas sem sugestão de correção apontam para desenvolvimento do sujeito pro- 
dutor em busca da proficiência textual, usando a reescrita como processamento do texto e não como mera didatização. Relacionado a essas alterações, o movimento de manutenção e o atendimento às sugestões de correção que geram as operações de reescrita são, como vimos, indicativos do funcionamento da reescrita textual em nível do ensino superior.

Podemos, dessa maneira, concluir que o funcionamento se dá essencialmente pelo engajamento do sujeito produtor nesse processo de reflexão sobre a escrita que é a reescrita. E esse engajamento, por sua vez, vai depender do grau de proficiência, de maturidade com a escrita desenvolvida, ou que deveria ter sido desenvolvida, ao longo da experiência escolar do sujeito recentemente ingresso no ensino superior e, também, do seu desenvolvimento cognitivo e de sua percepção das relações social-interativas. Fatores que lhe permitem pensar sobre o texto, desenvolvendo estratégias eficazes de autocorreção e de aproveitamento da correção realizada pelo professor.

\section{QUANDO A REESCRITA NÃO FUNCIONA}

Vimos singularidades advindas dos dados que apontam para o funcionamento da reescrita. Resta-nos, todavia, a outra face de singularidades que esses dados permitem observar: o não funcionamento da reescrita. Outra face, pois os fenômenos que a ela pertencem são, em sua maioria, de mesma base dos investigados anteriormente, mas que resultaram, por influências distintas, em aspectos do não funcionamento da reescrita.

Destacamos, inicialmente, o movimento de manutenção. Essa operação pode apresentar fatores favoráveis à reescrita, já analisados, assim como, fatores desfavoráveis, sobre os quais nos debruçamos agora, a partir de alguns fragmentos.

FRAGMENTO 5: E10

\section{Mostrándo) Xomo usar a língua de maneira adequada nas mais diversas situaçòes} da vida, no dia a dia e nos mais diversos graus de formalidade ou informalidade, adequando-se aos variados gêneros textuais aos quais devemos, queremos ou necessitemos produzir. 
FRAGMENTO 6: R10

\section{Mostrándo romo usar a}

língua de maneira adequada nas mais diversas situações da vida, no dia a dia e nos mais diversos graus de formalidade ou informalidade, adequando-se aos variados gêneros textuais aos quais devemos, queremos ou necessitemos produzir.

No fragmento 5: E10, há uma sinalização do corretor para que seja substituída a palavra mostrando por mostra; ao que tudo indica, a lógica utilizada pelo corretor para o aperfeiçoamento textual do aluno fundamenta-se na mudança da forma nominal em gerúndio do verbo mostrar pela forma verbal no presente, isso porque a palavra em questão situa-se no início de uma frase e, conforme convenções da escrita, esse emprego está em desacordo com a linguagem padrão (BECHARA, 2009). Ao passarmos nossa atenção ao fragmento 6: R10, fica clara a permanência da palavra mostrando na reescrita, não sendo substituída conforme fora indicado. Em outras palavras, parece que estamos diante de uma resistência do sujeito licenciando produtor em atender à sugestão de alteração do corretor que, diferentemente da manutenção realizada nos fragmentos 1: E10 e 2: R10, não contribui para a melhoria textual e sim para a manutenção de inadequações que deveriam ter sido solucionadas na reescrita. Três possíveis causas dessa manutenção nos foram reveladas pelos dados: (1) o sujeito produtor não concordou com a sugestão do corretor; (2) o sujeito produtor não compreendeu a sugestão, e (3) a falta de atenção do sujeito licenciando produtor ao reescrever.

Independentemente, contudo, da causa do movimento de manutenção, a experiência do sujeito licenciando produtor parece ser o fator comum e definitivo para a incorporação das modificações sugeridas ou para manutenção da proposta inicial. Cabe lembrar que a experiência do produtor aliada à indicação de correção do professor é que determinará se a manutenção é um movimento positivo ou negativo para a versão final do texto. Subtendem-se na manutenção, desse modo, dois fatores contribuintes para o não funcionamento da reescrita: a falta de maturidade e engajamento do sujeito escritor, como já pontuamos, e a correção, aspecto sinalizado no decorrer desta análise, no qual não nos detemos sistematicamente.

A correção, segundo apresentamos na fundamentação teórica deste estudo, de acordo com Ruiz (2001), é o trabalho realizado no texto do aluno pelo docente visando chamar a sua atenção para problemas de produção, podendo ser indicativa, resolutiva, classificatória e/ou textual-interativa. 
Dentre esses quatro tipos de correção, os que trariam melhores resultados para o texto e para o sujeito produtor seriam, em primeiro plano, segundo a autora citada, a textual-interativa, depois a classificatória, seguida da indicativa e da resolutiva. Ao analisarmos o corpus, atentando para essa questão, percebemos a existência de todas as formas de correção, com exceção da classificatória. Contudo, as três formas de correção não apareceram no corpus segundo essa lógica. No quadro a seguir, verificamos que a correção resolutiva é mais recorrente, ao contrário da textual-interativa.

Quadro 1. Tipos de correção e movimentos de reescrita

\begin{tabular}{|c|c|c|c|c|c|c|}
\hline \multirow[b]{2}{*}{ CORREÇÃO } & \multicolumn{5}{|c|}{ MOVIMENTOS DE REESCRITA } & \multirow{2}{*}{$\begin{array}{l}\text { Soma } \\
\text { por cor- } \\
\text { reção }\end{array}$} \\
\hline & $\begin{array}{l}\text { SUPRES- } \\
\text { SÃO }\end{array}$ & $\begin{array}{c}\text { ACRÉSCI- } \\
\text { MO }\end{array}$ & $\begin{array}{l}\text { DESLO- } \\
\text { CAMEN- } \\
\text { TO }\end{array}$ & $\begin{array}{l}\text { SUBSTI- } \\
\text { TUIÇÃO }\end{array}$ & $\begin{array}{l}\text { MANU- } \\
\text { TENÇÃO }\end{array}$ & \\
\hline $\begin{array}{l}\text { RESOLUTI- } \\
\text { VA }\end{array}$ & 31 & 73 & 3 & 114 & 52 & 273 \\
\hline INDICATIVA & 26 & 17 & 1 & 29 & 26 & 99 \\
\hline $\begin{array}{l}\text { TEXTUAL- } \\
\text { INTERATIVA }\end{array}$ & 16 & 23 & 0 & 11 & 15 & 65 \\
\hline $\begin{array}{l}\text { Soma por } \\
\text { movimento }\end{array}$ & 73 & 113 & 4 & 154 & 93 & 437 \\
\hline
\end{tabular}

No que se refere à relação entre correção e reescrita, chegamos aos resultados, postos no quadro acima. Averiguando as recorrências, temos a maioria incontestável da correção resolutiva (273), mais da metade do número total (437), seguida da correção indicativa (99) e, por fim, a correção textual-interativa (65). Uma relação totalmente inversa à tida como qualitativamente mais produtiva para o texto e para o sujeito, segundo apresentamos anteriormente.

A implicação dessa inversão é que o corretor, ao invés de contribuir para o amadurecimento do produtor, favorece, mesmo involuntariamente, à passividade do sujeito escritor por meio do(s) tipo(s) de correção utilizado(s). Na correção resolutiva, há a correção dos erros pelo professor, de modo que reescrever consiste em copiar as soluções não exigindo que o licenciando pense sobre a atividade; na correção indicativa, há a indicação do erro por alguma forma de grifo, cabendo ao aluno inferir o que deve ser feito especificamente, assim, ele pode não compreender a sinalização e deixar de reescrever por falta de entendimento e também por falta de 
proficiência; e na correção textual-interativa, temos comentários dos erros em forma de bilhetes. Essa seria, dentre todas as correções, a que traria melhores resultados qualitativos em relação ao texto e ao desenvolvimento de habilidades e raciocínio de escrita, todavia, foi, dentre as três, a correção menos recorrente no corpus analisado.

Trazidas essas considerações, somos levados a concluir que, ao priorizar correções indutoras de uma reescrita de baixo nível reflexivo em detrimento de um tipo de correção que supostamente traria mais reflexão para o produtor e modificações mais significativas no texto, o sujeito corretor está focado na melhoria das produções, mas não no desenvolvimento da proficiência do sujeito licenciando produtor nem no estímulo ao seu engajamento com a reescrita, já que este é levado a desempenhar um papel passivo.

Com isso, o professor corretor, ao invés de atuar como uma espécie de coautor, monopoliza o trabalho com o texto, tomando para si o dever de ler e de encontrar problemas e soluções, além de passar essa ideia para os graduandos. Dessa forma, nos parece que esses não são levados adequadamente à conscientização do processo de escrita e suas especificações, o que pode acarretar no não desenvolvimento de estratégias de melhoria textual a partir da autocorreção que se desencadearia com a internalização da atividade de reescrita e, como consequência, induziria à proficiência escritora dos sujeitos, ou seja, a reescrita seria tomada como parte do processo de escrita, não necessitando ser didatizada para ser realizada. Em outros termos, o sujeito licenciando produtor ainda não proficiente deixa de perceber a complexidade da escrita e mantém a concepção, trazida provavelmente da escola, de que reescrever é passar a limpo um texto: atividade esta basicamente só realizada a pedido do professor e conforme suas correções.

A análise do nosso corpus permite-nos também estreitar mais a relação entre os dois produtos do diálogo travado entre os sujeitos envolvidos: correção do professor e movimentos de reescrita do licenciando produtor. Esses produtos podem ser observados, quantitativamente, ao voltarmos ao Quadro 1, no qual vislumbramos algo que a literatura especializada não sinalizou, a abordagem da atividade de reescrita textual a partir da correlação entre os tipos de correção e os movimentos de reescrita. Observamos que tanto na correção resolutiva, quanto na indicativa, o movimento mais realizado pelos sujeitos produtores é o da substituição. Essa é uma das operações que requer menos esforço intelectual por parte do produtor, uma vez que se configura como modificação em nível paradigmático, superficial, geralmente troca por sinônimos, mas que cria a ilusão de que esse sujeito realizou uma reescrita.

Tomando ainda como referência o Quadro 1 anteriormente apresentado, a análise dos dados revela que, no segundo lugar, em números gerais, considerando os 
três tipos de correção, e em primeiro lugar no âmbito da correção textual-interativa, temos a operação de acréscimo. Não obstante essa coincidência, os dados indicam que essa operação é utilizada com propósitos diferentes. Nas correções resolutiva e indicativa, essa operação se consistiu, em sua maioria, de acréscimos microestruturais. Já na correção textual-interativa, aquela que levaria o produtor à reflexão sobre a escrita, o acréscimo ocorre em planos maiores (períodos e trechos), como no exemplo a seguir.

FRAGMENTO 7: E24

\begin{tabular}{|l|l|}
\hline & Esta obra é inovadora, uma vez que vê o texto, o funcionamento da \\
& linguagem e a fala de modo diferente do que já nos foi apresentado \\
& anteriormente por meio de outras obras com objetivos bem distintos, onde a \\
teoria exaustiva não apresentava situaçôes onde as mesmás poderiam ser
\end{tabular}

FRAGMENTO 8: R24

Esta obra vê o texto, o funcionamento da linguagem e a fala de modo diferente do que já nos foi apresentado anteriormente por meio de outras obras com objetivos bem distintos, onde a teoria exaustiva não apresentava situaçőes onde a mesma poderia ser aplicada de forma clara, interativa e ampla. Pois era apresentado aos professores superficialidades a respeito da produção escrita, esta por sua vez, vista ainda por um ângulo positivista.

Como vemos no Fragmento 8: R24, de uma resenha de nota oito, há um acréscimo de aproximadamente duas linhas ao final do parágrafo se o confrontarmos com o Fragmento 7: E24, no qual podemos ver a correção textual-interativa através de um comentário: "argumento final poderia ser mais aprofundado!". Pelo acréscimo na reescrita, supomos que o sujeito produtor do texto se engajou com a atividade, porém, por falta de experiência com o gênero ou com a escrita, não conseguiu cumprir plenamente o sugerido pela correção. O sujeito licenciando realiza, assim, um movimento de acréscimo em forma de anáfora discursiva remetendo-se para algo externo ao livro resenhado, quando deveria aprofundar o já colocado no parágrafo. Como vemos, trata-se de uma solução paliativa, isto é, uma saída imedia- 
ta e atenuante para o problema que necessitaria de mais proficiência desse sujeito. Uma "solução", portanto, que não contribuiu para a melhoria da produção final.

Os dados revelam que, quando se trata da correção textual-interativa, esses acréscimos superficiais são recorrentes, principalmente se a sugestão é para aprofundamento e reformulações da primeira versão do texto. Quando essa ação não é realizada, torna-se recorrente a supressão dos trechos problemáticos. Com essa atitude, o licenciando produtor pensa que resolveu o problema apresentado pela correção, entretanto, essa solução serve apenas para ele, pois, o texto perde, em muitos casos, em informação e argumentatividade.

Ao dar sequência à observação numérica e qualitativa dos dados, verificamos que, seguindo a escala decrescente, conforme o Quadro 1, o próximo elemento que nos aparece é a manutenção (terceira colocada nas correções resolutiva e textual-interativa e empatada em segundo lugar na correção indicativa), cujas motivações já discutimos. Passamos, então, aos penúltimos colocados em recorrência, nos quais observamos a maior variação, visto que na correção resolutiva temos a supressão; na indicativa, o movimento de acréscimo e na textual-interativa, a substituição. Ocorrências, essas, à primeira vista desconectadas, mas relacionadas logicamente conforme descrevemos a seguir. A resolutiva realiza menos apagamentos, porque se algo é visto pelo corretor como inadequado, a tendência é substituir a inadequação por elemento que melhor se encaixe no texto. A correção indicativa, por sua vez, realiza menos acréscimos por ser uma forma de correção de difícil sinalização deste movimento, devido ao fato de ter como recursos apenas sinalizações voltadas para aspectos estruturais do texto. Já a correção textual-interativa realiza menos substituições, pois é uma operação de difícil realização quando pensamos em trechos que deveriam ser reformulados.

Por fim, temos o movimento de reescrita menos realizado independente do tipo de correção: deslocamento. Apenas quatro ações foram identificadas nas 27 reescritas, como resultado de movimentos realizados a partir de uma sugestão de correção. Acreditamos que essa baixa incidência se deve à dificuldade de sinalizar e de realizar mudanças topográficas no texto, pois, essa modificação requer maior engajamento por parte do corretor com a tarefa sob sua responsabilidade e preocupação com os efeitos da mesma sobre a ação do escritor durante a reescrita. Além disso, esse mesmo movimento, quando sinalizado na correção, requer proficiência por parte do produtor e engajamento com a atividade de reescrita.

Resta-nos, além desses, outro aspecto influenciador do não funcionamento da reescrita na esfera acadêmica. Esse aspecto corresponde às alterações de reescrita voluntárias, ou seja, sem indicação de correção, que, assim como o movimento 
de manutenção, podem não contribuir para o funcionamento da reescrita devido à falta de maturidade do sujeito produtor para julgar a eficácia ou não de possíveis modificações, como bem exemplificam os fragmentos a seguir:

FRAGMENTO 9: E18

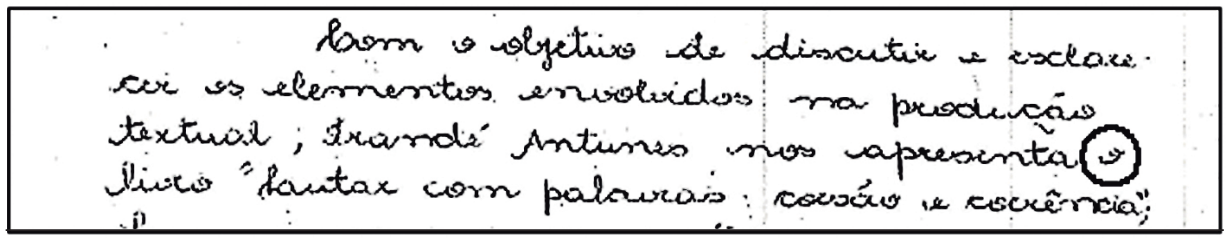

FRAGMENTO 10: R18

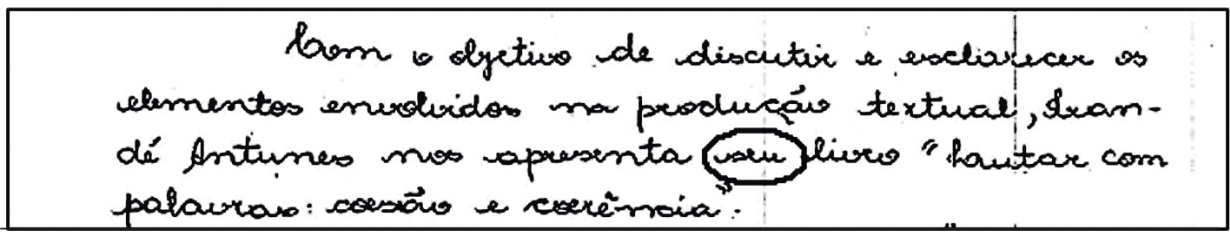

A substituição de o, no Fragmento 9: E18, por seu, no Fragmento 10: R18, não traz contribuições significativas para a versão final da resenha, é apenas uma maneira de o sujeito licenciando produtor sentir ter realizado a tarefa de reescrita.

Ao finalizar essa segunda seção de análise, salientamos que os fatores que contribuem para o não funcionamento da reescrita estão relacionados com os fatores contribuintes para o seu funcionamento, mas com focos diferenciados. Em outros termos, é a inexperiência do sujeito licenciando produtor que leva ao não funcionamento da reescrita. Aliado a esse fator, constatamos outro tão complexo e responsável pelo (não) melhoramento da reescrita quanto este: a correção realizada pelo sujeito corretor no texto do sujeito licenciando produtor.

No corpus analisado, encontramos em quinze, das vinte e sete produções iniciais, sugestões indicativas, resolutivas e textual-interativas, e, em apenas quatro delas verificamos um único tipo de correção. Não advogamos que o corretor utilize apenas um tipo, uma vez que, conforme demonstram nossos dados, os textos apresentam problemas de natureza diferenciada; mas inferimos que os produtores menos experientes parecem não saber o que privilegiar na reescrita quando se deparam com vários tipos de correção no mesmo trabalho.

Portanto, entendemos que a clareza da correção, assim como a significação negociada do seu papel, aliadas à experiência do produtor, parecem ser fatores indissociados que contribuem para o (não) funcionamento da reescrita. 


\section{FUNCIONA OU NÃO FUNCIONA: DISCUSSÃO GERAL DOS DADOS}

A reescrita textual caracteriza-se por sua essência complexa, tendo em vista a multiplicidade dos fatores nela envolvidos, desde aspectos cognitivos e linguísticos, até aspectos de ordem sociointeracionista, o que nos faz pensá-la como uma importante etapa do processo de produção textual. Sua noção, como expusemos brevemente na fundamentação teórica deste artigo, ora é apresentada como etapa associada internamente à escrita e realizada concomitante a esta (conforme as fundamentações teóricas de escrita), ora é definida como didatização do processo de escrita, efetivada após o "término" da produção por escritores ainda pouco proficientes sob a orientação escrita e não presencial de um corretor (segundo os trabalhos de viés didático sobre reescrita). O primeiro caso, é mais comum, dizem os autores, entre escritores com maior domínio do processo de escrita e que, consequentemente, já internalizaram a reescrita didatizada. No segundo caso, trata-se de uma tarefa escolar.

Independentemente, entretanto, da maneira de se pensar e realizar a reescrita, um objetivo permanece: reescrever como forma de melhoramento, tanto textual, quanto de formação proficiente e crítica do sujeito produtor. Contrapondo-se a essa perspectiva de melhoramento, contudo, indicativos levaram-nos a pensar que nem sempre a reescrita é bem sucedida.

Afinal, o que pode ser dito sobre o (não) funcionamento da reescrita em textos produzidos por licenciandos em Letras em seus períodos iniciais da graduação, a partir de atividades didáticas de produção de texto, com direito à reescrita como etapa que se realiza após a correção inicial do professor?

Inicialmente, a resposta prévia para uma questão como esta tende a se polarizar e a indicar dissociadamente os fatores que funcionam e os que não funcionam. Todavia, consideramos que a resposta é complexa e leva em consideração, de modo indissociado, os mesmos fatores que só podem ser avaliados em relação ao contexto em que foram produzidos, ou seja, a correção do sujeito docente corretor assim como a experiência do sujeito licenciando produtor são os fatores que podem influenciar tanto o funcionamento quanto o não funcionamento da reescrita. A faceta positiva ou negativa é determinada pelo contexto de produção e por elementos relacionados diretamente à reescrita: movimentos de reescrita descritos na literatura e sinalizados por correção (supressão, acréscimo, substituição e deslocamento), tipos de correção (textual-interativa, classificatória, indicativa e resolutiva), movimentos de reescrita voluntários (movimentos de supressão, acréscimo, substituição e deslocamento realizados sem indicação por correção) e movimento de manutenção (permanência 
na reescrita de um dado elemento sinalizado com passível de correção pelo corretor na escrita inicial).

Os dados mostram que a correção, juntamente com a consigna de reescrita, exercem influência sob o texto do licenciando, pois determinam o "caminho" que deve ser seguido, indicam que há uma tarefa a ser cumprida. Apesar de ter sido didatizada, entretanto, não encontramos comandos explícitos de reescrita nas produções analisadas, esses foram, na maioria das vezes, tácitos, revelados por alguma interação face-a-face, de modo que os escritores não proficientes iniciantes do ensino superior não foram devidamente guiados como pressupõe uma reescrita didatizada. Verificamos, também, que uma mesma escrita recebeu do mesmo corretor diferentes tipos de correção, ou seja, o sujeito corretor não tinha um tipo de correção específico, e isso não constitui, por si só, um fator negativo nem positivo. Todavia, quando observamos os tipos mais recorrentes, constatamos um favorecimento à passividade do sujeito licenciando produtor.

A forma de correção quantitativamente mais expressiva foi a resolutiva, que significa um trabalho menor do ponto de vista da reflexão para quem reescreve, isso porque o corretor já soluciona a inadequação restando ao escritor apenas o exercício de copiar. A correção indicativa, a segunda numericamente identificada, apesar de apresentar alguma diferença em relação à resolutiva, também contribui para a passividade. Por fim, tivemos a correção textual-interativa. Essa é apontada, há algum tempo, como a que melhor cumpre com os objetivos da reescrita textual. Entretanto, foi a menos utilizada pelo corretor.

Em oposição a esse, aparece o outro fator determinante, isto é, a experiência com a escrita por parte do sujeito produtor que o leva a criar uma tensão com o processo de escrita e leva-o a romper com passividade. A posição em que o corretor coloca o sujeito escritor é, frequentemente, a de passividade, na qual ele está desligado da sua função de produtor. Todavia, essa função tende a ser interessantemente reestabelecida pelo engajamento demonstrado pelo sujeito licenciando ao se deparar com a atividade de reescrita. Esse sujeito empenha-se ao ponto de realizar alterações mesmo sem sugestão de correção e movimentos voluntários de manutenção que superam, numericamente, as operações realizadas de maneira a executar uma correção feita pelo professor.

Esse engajamento alia-se à experiência, à proficiência do produtor, ou seja, o sujeito está lidando ao mesmo tempo com o tema, estilo e composição numa esfera específica (a academia), para um interlocutor específico que é o professor, assim tem que apresentar demonstrações de maturidade. Portanto, apenas o engajamento não é fator que garante uma boa reescrita; esse deve estar associado à proficiência 
dos produtores que o guiará na atividade de ler, refletir, ponderar, buscar a melhoria linguística e discursiva dos seus textos.

Quando não se tem essa maturidade associada à forma de correção preponderante, o sujeito tende a não realizar a reescrita enquanto atividade de melhora da qualidade do texto. A reescrita é feita, mas parece manter-se num nível de atividade escolar, na qual o sujeito elimina um problema, mantém o problema ou simplesmente passa a limpo, porque já tem a resposta. Comparativamente, outros sujeitos, mesmo com o auxílio apenas de uma correção indicativa, que é tida como menos expressiva do ponto de vista didático, realizaram uma boa reescrita, dando demonstrações de que ela passou de uma atividade pedagógica de ensino de escrita para uma etapa do processo de escrita.

Entretanto, essa atividade também funciona, como dissemos, se pensarmos no engajamento dos sujeitos licenciandos produtores e nas demonstrações de proficiência.

Desse modo, ao lado do engajamento do escritor, a correção parece ter uma influência significativa sobre a reescrita. $\mathrm{O}$ quadro a seguir sintetiza os dois fatores identificados como mais relevantes para o (não) funcionamento da reescrita: a atitude voluntária do escritor e as indicações da correção. Esses fatores estão correlacionados aos movimentos de reescrita, conforme pode ser visto na sequência.

Quadro 2. Alterações voluntárias e alterações indicadas

\begin{tabular}{|c|c|c|c|c|}
\cline { 2 - 5 } \multicolumn{1}{c|}{} & \multicolumn{4}{c|}{ MOVIMENTOS DE REESCRITA } \\
\cline { 2 - 5 } \multicolumn{1}{c|}{} & SUPRESSÃO & ACRÉSCIMO & $\begin{array}{c}\text { DESLOCA- } \\
\text { MENTO }\end{array}$ & $\begin{array}{c}\text { SUBSTITUI- } \\
\text { ÇÃO }\end{array}$ \\
\hline $\begin{array}{c}\text { ALTERAÇÕES } \\
\text { VOLUNTÁ- } \\
\text { RIAS }\end{array}$ & 74 & 132 & 27 & 119 \\
\hline $\begin{array}{c}\text { ALTERAÇÕES } \\
\text { INDICADAS }\end{array}$ & 73 & 113 & 4 & 154 \\
\hline
\end{tabular}

Como se pode observar, o Quadro 2 expõe uma síntese dos dados. Numericamente, os resultados desse quadro podem não ser considerados expressivos, pois temos nas duas primeiras colunas números aproximados e temos uma diferença significativa na terceira e quarta colunas. São justamente esses dois últimos resultados que nos interessam e ratificam os resultados anteriormente apresentados.

Verificamos que 154 movimentos de substituição realizados nas 27 produções analisadas resultam de indicações da correção. Ora, esse dado ratifica o papel 
do corretor nos dados analisados, qual seja, o da opção pela correção resolutiva, pois, dessas 154 substituições, 114 resultam da correção resolutiva, ou seja, o corretor opta, consciente ou inconscientemente, por oferecer ao licenciando um papel de maior passividade na atividade de reescrita. Por outro lado, temos 119 correções do tipo substituição que resultam da atitude voluntária dos escritores. Logo, esses dados nos levam a inferir que o movimento de substituição parece ter sido assimilado como aquele que melhor descreve para o grupo em apreço a atividade focalizada. Substituir parece ser sinônimo de melhorar. A diferença percentual de $23 \%$ entre a indicação e a iniciativa revela que os sujeitos acompanhados indiretamente neste estudo mantinham uma atitude pró-ativa em relação à reescrita.

Todavia, os dados relacionados ao deslocamento dão-nos ainda mais indicação dessa atitude pró-ativa, pois temos 27 deslocamentos feitos por iniciativa voluntária dos escritores, na segunda versão de seus textos, contra 4 deslocamentos indicados pelo corretor. Esses dados parecem nos indicar que houve um envolvimento coletivo com a atividade de reescrita por parte do grupo. O deslocamento, ao contrário da substituição, é um movimento mais difícil de ser realizado por que altera topograficamente determinados trechos do texto original, levando, muitas vezes, a outras alterações de ordem sintática e microestrutural. Ou seja, deslocar de modo a melhorar o texto é um movimento feito por um sujeito engajado e, aparentemente, maduro.

Uma visão coletiva dos dados, em síntese, permite inferir que os aprendizes se envolveram mais com a atividade de reescrita do que fazia sugerir a correção de texto que lhe foi apresentada. O grupo de sujeitos investigado passou a se envolver com a atividade de produção textual atribuindo grande importância à reescrita, pois, mesmo uma produção que havia recebido uma nota alta e poucas sinalizações de reescrita foi retrabalhada pelo licenciando produtor através de todos ou quase todos os movimentos de reescrita. De modo geral, essa tendência se apresenta no conjunto de dados, portanto, o engajamento do escritor associado à maturidade relativa à composição textual parecem ser fatores determinantes para o funcionamento da reescrita como atividade didática.

\section{CONCLUSÕES}

Corroborando as análises e discussões levantadas, podemos dizer que a reescrita parece funcionar mais pela maturidade linguístico-cognitivo-interacional dos sujeitos produtores que pelo estímulo do corretor. Com essa conclusão nos vem 
uma indagação: se a reescrita depende essencialmente da proficiência e engajamento do sujeito licenciando produtor, então se este sujeito não tiver essas características não conseguirá reescrever seu texto? Aqui é que se faz importante a relação dialógica estabelecida entre licenciando e professor. A reescrita pode desenvolver as habilidades do licenciando não proficiente quando guiada por uma correção que auxilia na construção de novas competências textuais por parte do sujeito.

Um mesmo fator, assim, pode ou não funcionar. Em outros termos, a reescrita em si não é boa nem é má, ela vai funcionar ou não dependendo desses dois grandes fatores instáveis que dependem dos dois sujeitos envolvidos: correção do professor e experiência individual do licenciando, de maneira que acenar positiva ou negativamente sem considerar esses fatores é negar a complexidade do processo de escrita. Tal consideração nos permite pensar que a reescrita não existe por si só, independente dos sujeitos que as utilizam em situações diversas e com propósitos igualmente variados. Ao contrário, essa etapa da elaboração textual resulta das relações estabelecidas entre sujeito produtor e seu leitor interno, sujeito corretor e o texto, envolvendo complexamente aspectos de níveis diversos.

As considerações que levantamos implicam também que o exercício pedagógico da reescrita parece necessitar ser mais bem trabalhado no curso de Letras, apesar de termos consciência de que a maturidade textual é um processo não homogêneo e individual que começa a ser desenvolvido, ou não, desde as séries iniciais da escolarização. Essa seria uma vertente para estudos posteriores: analisar o desenvolvimento das habilidades de reescrita extra-academia que influenciaram os sujeitos na academia. Podemos vislumbrar, também, outra possibilidade: verificar se os sujeitos licenciandos dos períodos iniciais, ao avançarem na vida acadêmica, desenvolvem (como e por que) estratégias de reescrita. Isso permitiria novas contribuições para os estudos sobre reescrita e sobre a escrita em nível superior de ensino.

A reescrita, por fim, convoca um saber-fazer, saberes linguísticos e extralinguísticos de articulação e negociação visando melhorar e retrabalhar o texto ao mesmo tempo em que desenvolve esse saber-fazer. Uma relação de mão dupla que nos remete à resposta, em poucas palavras, de uma pergunta levantada por Clarice Lispector "Como é que se escreve?" (LISPECTOR, 2003): "Escrevendo" se escreve, e reescrevendo apropria-se da escrita, internalizando seu processo.

\section{REFERÊNCIAS BIBLIOGRÁFICAS}

ANTUNES, I. (2003). Aula de Português: encontros \& interações. São Paulo: Parábola Editorial. BECHARA, E. (2009). Moderna gramática portuguesa. Rio de Janeiro: Nova Fronteira. 
CÁLIS, O. G. T. (2008). A reescrita como correção: sobras, ausências e inadequações na visão de formandos em Letras. 2008. Dissertação de Mestrado. - Universidade de São Paulo - USP. São Paulo, SP. 2008. Disponível em: < http://www.teses.usp.br/teses/disponiveis/8/8142/tde-15092008-145159/pt-br.php> Acesso em: 9 out. 2010.

GAFFURI, P.; MENEGASSI, R. J. (2010). Responsividade na revisão e reescrita: a quebra dos elos no diálogo escrito. In: $1^{\circ}$ Colóquio Internacional de Estudos Linguísticos e Literários / $4^{\circ}$ Colóquio de Estudos Linguísticos e Literários. 2010. Maringá. Anais. Maringá: UEM. Disponível em: <http://www.cielli.com.br/downloads/589.pdf> Acesso em: 16 jan. 2011.

HAYES, J. R; FLOWER, L. (1980). Identifying the organization of the writing processes. In: Gregg, L.W.; Steinberg, E. R. (eds.). Cogntive processes in writing. Hillsdale: Erlbaum.

JESUS, C. A. de. (1995) Reescrevendo o texto: a higienização da escrita. In: Chiappini, L. (coord.). Aprender e ensinar com textos. São Paulo: Marca d’Água. pp. 87-100.

KATO, M. (1993). No mundo da escrita: uma perspectiva psicolinguística. São Paulo: Ática.

LISPECTOR, C. (2003). Como é que se escreve?. In: Pequenas descobertas do mundo. Rio de Janeiro: Racco.

MEURER, J. L. (1997). Esboço de um modelo de produção de textos. In: Meurer, J. L.; Motta-Roth, D. (orgs.). Parâmetros de textualização. Santa Maria: Editora da UFSM.

MOREIRA, H, CALEFFE, L. G. (2006). Metodologia da pesquisa para o professor pesquisador. Rio de Janeiro: DP\&A.

RUIZ, E. M. S. D. (2001). Como se corrige redação na escola. Campinas, São Paulo: Mercado de Letras. (Coleção Ideias sobre Linguagem).

SAUTCHUK, I. (2003). A produção dialógica do texto escrito: um diálogo entre escritor e leitor interno. São Paulo: Martins Fontes (Coleção Texto e Linguagem).

Recebido: 15/03/2013

Aceito: 17/04/2014 